\title{
Denizli ve çevresi maksillofasiyal kırıkların son 5 yıllık epidemiyolojik analizi
}

\author{
Last 5 years epidemiological analysis of maxillofacial fractures in Denizli and its \\ surrounding
}

Büşra Gedik Toprak, Enver Arpacı

Gönderilme tarihi:29.07.2021

Kabul tarihi:05.11.2021

\section{Öz}

Amaç: Maksillofasiyal travmaların epidemiyolojisi, farklı ülkelerde ve coğrafi bölgelerde değişiklik gösterir. Nüfus yoğunluğu, yaşam tarzı, kültürel geçmiş ve sosyoekonomik durum, maksillofasiyal travmaların prevalans ve etyolojisini etkileyebilir. Bu çalışmanın amacı retrospektif olarak yüz kırıklarının tespit edilmesi, gerekli önlemlerin alınması ve olası cerrahi yoğunluk yükünün belirlenmesidir.

Gereç ve yöntem: Şubat 2015 ile Eylül 2020 arasında maksillofasiyal travma nedeniyle Pamukkale Üniversitesi Tıp Fakültesi Plastik Cerrahi Anabilim Dalı bünyesinde tedavi edilen 4-70 yaş aralığındaki 107 hasta retrospektif olarak incelendi. Hastalar yaş, cinsiyet, travmanın yıllara, aylara ve mevsimlere göre dağılımı, etyolojisi, eşlik eden ek travmalar ve fraktürlerin anatomik dağılımları kriterlerine göre değerlendirilerek gruplara ayrıldı ve karşılaştırıldı.

Bulgular: Yüz kırığına maruz kalan erkek/kadın oranının 4,6/1 ve en sık 21-30 yaş aralığında olduğu tespit edildi. Travmalar en çok yaz mevsiminde (özellikle Haziran ve Eylül aylarında) meydana geldi. Yüz kırıkları en sık orta yüz kemik bölgesinde $(\% 51,2)$ tespit edildi. Orta yüz alt grupları ve diğer yüz bölgesi kırıkları karşılaştırıldığında, mandibula kırıkları daha yüksek orana sahipti (\%35.5), bunu orbita duvar kırıkları takip etti (\%31.3). En sık görülen etiyolojik faktör trafik kazası, ikinci sıklıkta düşme tespit edildi. En sık ortopedik travmaların eşlik ettiği görüldü.

Sonuç: Trafik kazalarının etyolojik nedenin çoğunluğunu oluşturduğu çalışmamızda, özellikle motor kazaları dikkati çekmektedir. Ülkemizde kask kullanımı, yol güvenliği ve trafik kontrollerinin artırımasının, meydana gelecek kazaları ve maksillofasiyal travmaları azaltmasındaki etkisi önemlidir.

Anahtar kelimeler: Maksillofasiyal, orta-yüz, mandibula, kırık.

Gedik Toprak B, Arpacı E. Denizli ve çevresi maksillofasiyal kırıkların son 5 yıllık epidemiyolojik analizi. Pam Tıp Derg 2022;15:331-336.

\begin{abstract}
Purpose: The epidemiology of maxillofacial trauma varies in different countries and geographical regions. Population density, lifestyle, culture and socioeconomic status can affect the prevalence and etiology. The aim of this study is to retrospectively detect facial fractures, take the necessary precautions and determine the surgical density burden.

Materials and methods: Between February 2015-September 2020, 107 patients aged 4-70 years in the Pamukkale Universty School of Medicine Department of Plastic Surgery due to maxillofacial traumas were retrospectively analyzed. The patients were divided into groups, analyzed and compared according to criteria of age, gender, distribution of trauma by years, months and seasons, etiology of trauma, accompanying traumas and anatomical distribution of fractures.

Results: The ratio of men/women was 4.6/1. The most common age group was 21-30. Traumas most often occurred in the summer (June-September). According to facial regions, the most common fractures were in the midface region (51.2\%). Mandible fractures had $35.5 \%$ higher rate, following by orbital wall fractures $31.3 \%$, as midface subgroups and other facial area fractures were compared. The most common etiology was traffic accidents and falling was the second.It was observed that orthopedic traumas were the most common accompanying.

Conclusion: In our study, in which traffic accidents constitute the majority of the etiological cause, especially motor accidents draw attention. The effect of increasing helmet use, road safety and traffic controls are important in reducing accidents and maxillofacial traumas.
\end{abstract}

Key words: Maxillofacial, mid-face, mandible, fracture.

Gedik Toprak B, Arpaci E. Last 5 years epidemiological analysis of maxillofacial fractures in Denizli and its surrounding. Pam Med J 2022;15:331-336.

Büşra Gedik Toprak, Arş. Gör. Dr. Pamukkale Üniversitesi Tıp Fakültesi, Plastik ve Rekonstrüktif Cerrahisi Anabilim Dalı, Denizli, Türkiye, e-posta: busragedik4@gmail.com (https://orcid.org/0000-0003-2482-3389) (Sorumlu Yazar)

Enver Arpacı, Dr. Öğr. Üye. Pamukkale Üniversitesi Tıp Fakültesi, Plastik ve Rekonstrüktif Cerrahisi Anabilim Dalı, Denizli, Türkiye, e-posta: enverarpaci@yahoo.com (https://orcid.org/0000-0001-6713-8387) 


\section{Giriş}

Sayısal olarak etkilenen insan popülasyonu değerlendirildiğinde, travmanın dünya çapında önemli bir halk sağlığı sorunu oluşturduğu görülmektedir [1]. Yüz yaralanmaları, vücudun diğer bölgelerindeki yaralanmalarla birlikte veya izole acil servise başvuruların çoğunluğunu oluşturan ve cerrahi tedavi gerektiren travma türlerinden biridir.

Yüz bölgesindeki kemik yapıların bütünlüğünün bozulduğu travmalarda görme, solunum, çiğneme ve konuşma gibi fonksiyonel bozuklukların yanı sıra estetik görünüm açısından da ciddi deformiteler oluşmaktadır [2]. Yüz kemiği kırıklarının nedenleri ve etkilenen anatomik bölgelerin analizi, gelecekte meydana gelecek kırıkların önlenmesi ve tedavi stratejileri ile ilgili önemli ipuçları sağlar.

$\mathrm{Bu}$ çalışmanın amacı Denizli ili ve çevresinde meydana gelen yüz kemik kırıkları ve travmalarının retrospektif olarak incelenerek demografik özelliklerinin ortaya konulmasıdır.

\section{Gereç ve yöntem}

Pamukkale Üniversitesi Tıp Fakültesi, Plastik, Rekonstrüktif ve Estetik Cerrahi bölümü tarafından maksillofasiyal fraktür teşhisi ile kapalı redüksiyon, açık redüksiyon ve/ veya internal fiksasyon uygulanan 107 hasta retrospektif olarak incelendi. Bu çalışma için Pamukkale Üniveritesi Girişimsel Olmayan Klinik Araştırmalar Etik Kurulu'ndan etik onayı alınmıştır. Değerlendirmeye alınan kriterler hasta sayısı, yaş grubu, cinsiyet, travmanın yıl, ay ve mevsimlere göre dağılımı, travmaların etyolojisi, eşlik eden travma ve fraktürlerin anatomik dağılımlarıydı.
Hasta yaşları on yıllık dekadlara bölünerek incelendi.

Travma etyolojisine göre yedi kategori belirlendi. Bunlar darp, araç içi trafik kazası (AITK), araç dışı trafik kazası (ADTK), düşme, ateşli silah yaralanması (ASY), iş kazası ve diğerleri şeklindeydi.

Maksillofasiyal fraktürlere eşlik eden travmalar ortopedik, torakal, intraabdominal, kraniyal-intrakraniyal-vertebral, orbitalperiorbital yaralanmalar ve izole vakalar olarak alt gruplara ayrıldı. Eşlik eden travmaların etyolojik faktörler ile ilişkisi incelendi (Tablo 1).

Kemik kırıkları orta yüz ve mandibular kemik kırıkları şeklinde sınıflandırıldı. Orta yüz kemik kırıklarının dağılımı Tablo 2'de özetlenmiştir. Mandibula kırıkları; dentoalveolar, simfiz, parasimfiz, corpus, angulus, ramus, kondil boynu, subkondil, kondil ve coronoid alt grupları şeklinde sınıflandııılı (Tablo 3). Kırık sayısı hasta sayısından bağımsız olarak birden fazla kırığa sahip vakalarda ayrı şekilde hesaplandı. Orta yüz kemik kırıkları içerisinde yüzde asimetriye yol açan 11 zygomatik ark fraktürüne kapalı redüksiyon uygulandı. Diğer bölge kırıklarında ise açık redüksiyon internal fiksasyon tercih edildi.

\section{Bulgular}

Toplam 107 hastanın 88'i $(\% 82,2)$ erkek, 19'u $(\% 17,8)$ kadındı. Hastaların yaş aralığı 4-77 ve en sık ortalama 21-30 yaş aralığındaydı (Tablo 3). Erkek/kadın oranı 4,6/1 olarak tespit edildi.

Kırık insidansı 2015'de $22(\% 21,4)$ ve 2016 'da 20 hasta $(\% 18,6)$, ardından 2017 'de 10 hasta $(\% 9,3)$ olarak tespit edildi. 2018 'de 13 hasta $(\% 12,1), 2019$ 'da 19 hasta $(17,7)$ ve

Tablo 1. Eşlik eden multi travmalar ve etyolojik faktörler arası ilişki

\begin{tabular}{|c|c|c|c|c|c|c|c|}
\hline \multirow[b]{2}{*}{ Eşlik Eden Travmalar } & \multicolumn{7}{|c|}{ Etyoloji } \\
\hline & ADTK & AITK & Düşme & Darp & ASY & İş Kazası & Toplam \\
\hline Ortopedik Travmalar & 12 & 6 & 3 & - & - & 2 & 23 \\
\hline İntraabdominal Yaralanmalar & 1 & 1 & 2 & - & - & - & 4 \\
\hline $\begin{array}{l}\text { Kraniya-İntrakraniyal-Vertebra } \\
\text { Yaralanmaları }\end{array}$ & 8 & 2 & 3 & - & - & 1 & 14 \\
\hline Toraks Yaralanmaları & 8 & 4 & 2 & - & - & - & 14 \\
\hline Göz veya Göz Kanalı Hasarı & - & - & 3 & - & - & - & 3 \\
\hline
\end{tabular}

AITK: Araç içi trafik kazası, ADTK: Araç dışı trafik kazası, ASY: Ateşli silah yaralanması 
Tablo 2. Orta yüz kemik kırıklarının anatomik konumlarının sıklığı

\begin{tabular}{ll}
\hline Kırık hattı saptanan bölge & Hasta sayısı \\
\hline Nasal Kemik & 0 \\
Orbital Duvar & 16 \\
Zigomatik Ark & 3 \\
Maksiller Duvar & 3 \\
$\mathrm{~N}+\mathrm{O}$ & 0 \\
$\mathrm{~N}+\mathrm{Z}$ & 1 \\
$\mathrm{~N}+\mathrm{M}$ & 2 \\
$\mathrm{O}+\mathrm{Z}$ & 3 \\
$\mathrm{O}+\mathrm{M}$ & 11 \\
$\mathrm{Z}+\mathrm{M}$ & 3 \\
$\mathrm{~N}+\mathrm{O}+\mathrm{Z}$ & 0 \\
$\mathrm{~N}+\mathrm{O}+\mathrm{M}$ & 2 \\
$\mathrm{O}+\mathrm{Z}+\mathrm{M}$ & 7 \\
$\mathrm{~N}+\mathrm{O}+\mathrm{Z}+\mathrm{M}$ & 11 \\
Toplam & 62 \\
\hline
\end{tabular}

$\mathrm{N}$ : Nasal kemik, O: Orbital duvar, Z: Zigomatik ark.

M: Maksiller duvar olarak sunulmuştur

Tablo 3. Mandibula kırıklarının anatomik konumlarının sıklığı

\begin{tabular}{ll}
\hline Fraktürün Yeri & Hasta Sayısı \\
\hline Dentoalveolar & 3 \\
Simfiz & 7 \\
Parasimfiz & 29 \\
Corpus & 18 \\
Angulus & 17 \\
Ramus & 12 \\
Kondil Boyun & 1 \\
Subkondil & 1 \\
Kondil & 13 \\
Coronoid & 3 \\
Toplam & 104 \\
\hline
\end{tabular}

2020 'de 23 hasta $(21,4)$ ile hasta sayısının yeniden artıığı görülmüştür (Şekil 1).

Yüz kırığı olan hastaların sıklığı da mevsimlere göre; sonbahar ( $\mathrm{n}=27, \% 25,2)$, kış $(n=12, \% 11,2)$, ilkbahar $(n=30, \% 28)$ ve yaz $(n=38, \% 35,5)$ olarak sınıflandıııldı (Şekil 2). En yüksek kırık oranı yaz aylarında $(\% 35,5)$ meydana geldi. Nitekim en yüksek oranlar Eylül $(\% 14)$ ve Haziran $(\% 14,9)$ aylarında rapor edilmiştir. En düşük oran ise Aralık $(\% 2,8)$ ayında kaydedildi.
Çalışmaya dahil edilen 107 hastada 166 kırık saptandı. En fazla kırık tespit edilen anatomik bölge \%35,5 ile mandibula kırıkları, ardından $\% 31,3$ ile orbital kemik kırıkları (Orbita duvarları ve blow-out fraktürü) olarak tespit edildi. Kırıklar izole ve diğer kırıklarla birlikte değerlendirildi. Orta yüz ve mandibula ayrı ayrı ele alındığında, orta yüz kemik kırıkları mandibula kırıklarına göre daha yüksek bir orana sahipti. Hastaların $\% 51,2$ 'sinde sadece orta yüz kırıkları ve $\% 37,1$ 'inde sadece mandibula kırıkları mevcuttu. Eş zamanlı orta yüz ve mandibula kırığı insidansı \%11,5 idi (Tablo 3, 4). 


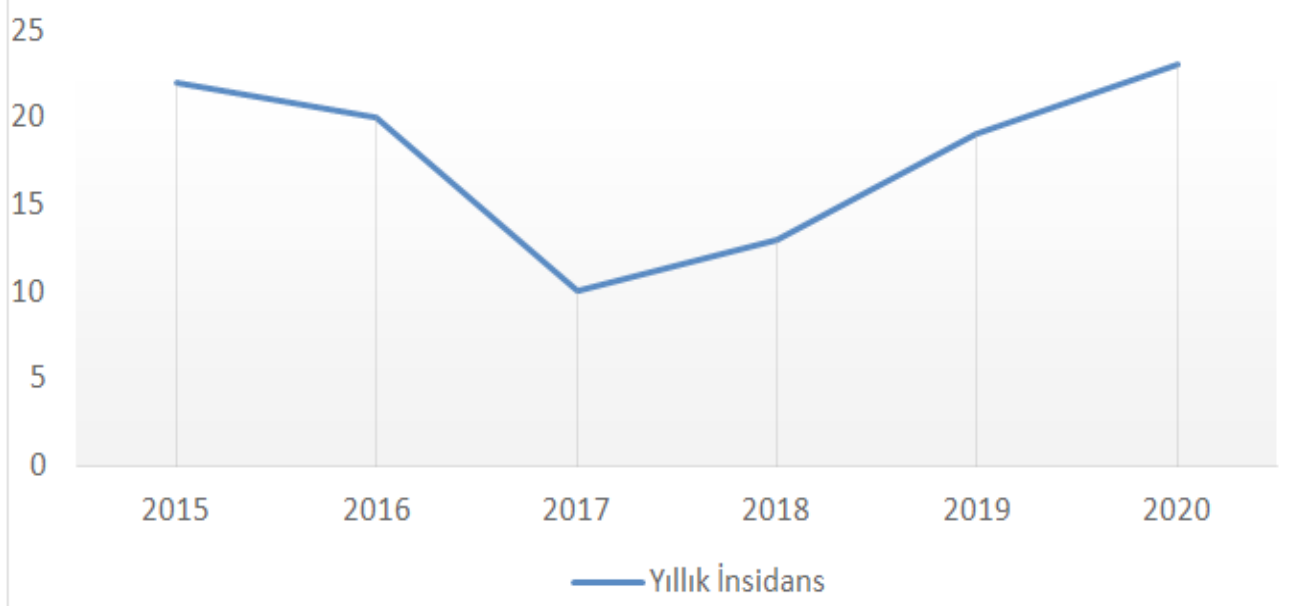

Şekil 1. Yıllara göre hasta dağılımı

Tablo 4. Sayı ve yüzdelerin yaş grubuna göre dağılımı

\begin{tabular}{lcc}
\hline Yaş Grubu & Hasta Sayısı & Hasta Yüzdesi \\
\hline $0-10$ & 7 & 6,5 \\
$11-20$ & 15 & 14 \\
$21-30$ & 28 & 26,1 \\
$31-40$ & 15 & 14 \\
$41-50$ & 18 & 16,8 \\
$51-60$ & 14 & 13 \\
$61-70$ & 8 & 7,4 \\
$71-80$ & 2 & 1,8 \\
$81-90$ & 0 & 0 \\
\hline
\end{tabular}

Trafik kazaları (AiTK ve ADTK), maksillofasiyal travma ile ilişkili ana etiyolojik faktördüf $(\% 46,7)$. ADTK'nın $\% 75$ 'i motor kazaları şeklindeydi. Düşme ise \%26,1 ile ikinci sıklıktaki etyolojik faktördür.

\section{Tartışma}

Maksillofasiyal travma insidans oranı son yıllarda dünya çapında artmaktadır [3]. Yüz bölgesi açıkta ve korunmasız olduğu için diğer travma türlerine göre daha yüksek morbidite oranına sahiptir [2]. Yüz travmalarının çoğu oklüzyonel fonksiyon sorunları, şekil bozuklukları, yüz felci, görme, işitme ve çiğneme sorunları gibi problemlere neden olmaktadır. Sonuç olarak, maksillofasiyal kırıklar ve bunların komplikasyonları hastaların yaşam kalitesini ciddi şekilde etkileyerek büyük sosyal ve ekonomik yüklere yol açmaktadır [2].

Maksillofasiyal fraktürlerin insidansı, etiyolojisi, tipleri ve ilişkili yaralanmaları, insanlar arasındaki çevresel, sosyoekonomik, kültürel ve yaşam tarzı farklııklarından dolayı farklı ülkeler ve hatta aynı ülkenin farklı bölgeleri arasında farklılık göstermektedir [4-6].

Çalışmamızda maksillofasiyal fraktürden etkilenen erkek popülasyon oranı, literatür ile uyumlu olarak kadın cinsiyete göre daha yüksek tespit edilmiştir [4, 7-11]. Öte yandan Grönland, Finlandiya ve Avusturya gibi kadınlar için daha fazla sosyal özgürlüğe sahip ülkelerde daha az farkla seyretmektedir [12].

Çalışmamızda en yüksek kırık insidansının 3. dekad içinde olduğu gösterilmiştir $(\% 26,1)$. Benzer şekildeki çalışmalarda da bu yaş gurubundaki hastalarda travma sıklığının daha fazla olduğu görülmektedir [13]. Bu yaş grubunda fiziksel ve sosyal aktivitenin daha fazla olmasından dolayı yüksek bir kırık insidansının da ortaya çıkması olasıdır.

Çalışmamıza dahil edilen maksillofasiyal kırıkların etiyolojisinde en sık nedenin trafik kazaları olduğu ortaya çıkmıştır ve bu 


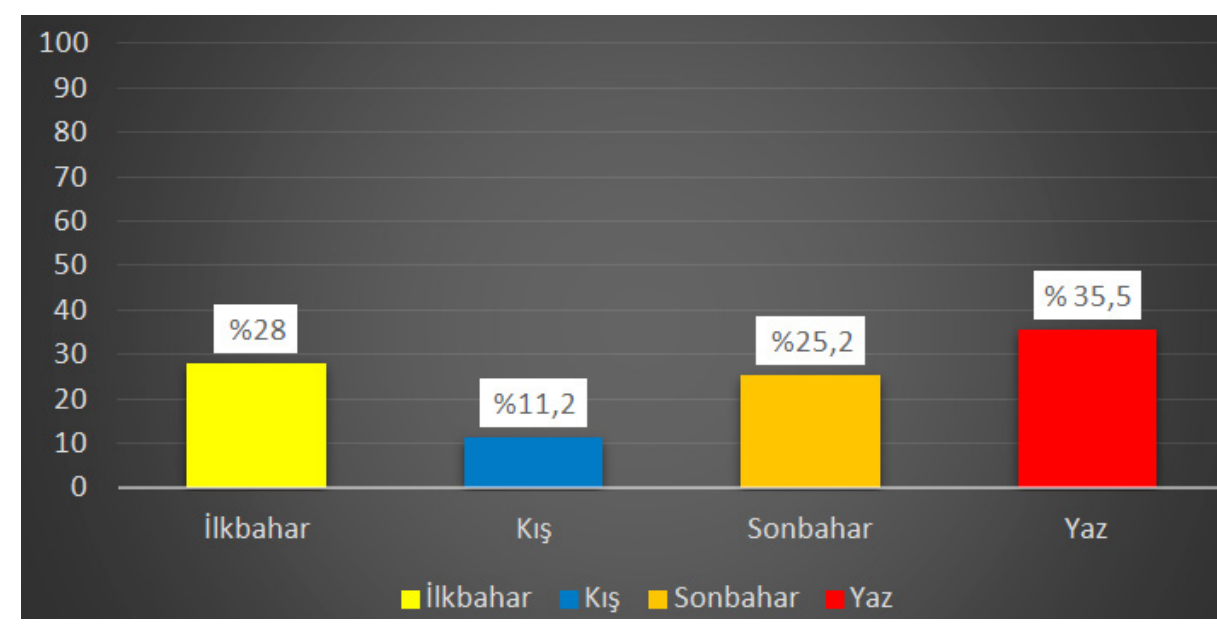

Şekil 2. Mevsimlere göre hasta yüzdesi

literatür bilgisi ile uyumludur [14-16]. Diğer yandan, darp sonrası oluşan maksillofasiyal yaralanmaların gelişmiş ülkelerde daha yaygın olduğu bildirilmiştir $[17,18]$. Çalışmamızda darp sonucu oluşan maksillofasiyal kırıklar, vakaların $\% 12,1$ 'ini oluşturuyordu.

Gelişmiş ülkelerde emniyet kemeri, motosiklet kaskı gibi koruyucu önlemlerin artan kullanımı ve sıkı bir şekilde uygulanan trafik kuralları kontrolü, trafik kazalarına bağlı maksillofasiyal kırıkların insidansında bir azalma ile ilişkilendirilmiştir [19]. Bir ulaşım şekli olarak motosiklet kullanımındaki artış maksillofasiyal yaralanmaları önemli ölçüde etkilemiştir [4, 20].

Bu çalışmada mandibula ve orta yüz kırıkları ayrı olarak kendi içlerinde gruplandırıldı. İzole orta yüz kemiği kırığına sahip olan hastaların, izole mandibula kırığına sahip olan hastalardan daha fazla olduğu görüldü.

Travmaların yaz mevsiminde daha $s ı k$ olduğu ve özellikle Haziran ile Eylül aylarında meydana geldiği tespit edildi. Bunun nedeninin, ülkemizde yaz tatili başlangıcı ve sonu olan bu aylarda tatile gidiş ve dönüş amaçı kullanılan araç sayısı ve trafik kazalarının artmasından kaynaklandığı düşünüldü.

Bazı çalışmalarda en sık eşlik eden travma türünün kafa travmaları olduğu, diğer bazı çalışmalarda ise ortopedik travmalar olduğunu bildirilmiştir [3]. Bizim çalışmamızda en sık eşlik eden travma türünün ortopedik kaynaklı olduğu ortaya çıkmıştır. Ardından kraniyal-intraktaniyal ve vertebra travmaları izledi. Etiyolojik sebeplerin en sık trafik kazaları, düşme ve darp olduğu göz önünde bulundurulduğunda, eşlik eden travma türlerinin yukarıda belirtilen şekilde olması olağan olarak kabul edilebilir.

Sonuç olarak bu çalışmada, trafik kazalarının etyolojik faktörlerin başında yer aldığı görülmüştür, özellikle trafik kazaları içinde motor kazaları dikkati çekmektedir. Ülkemizde kask kullanımı, yol güvenliği ve trafik kontrollerinin artırımasının, meydana gelecek kazaları ve maksillofasiyal travmaları azaltmasındaki etkisi önemlidir.

Çıkar ilişkisi: Yazarlar çıkar ilişkisi olmadığını beyan eder.

\section{Kaynaklar}

1. Viozzi CF. Maxillofacial and mandibular fractures in sports. Clin Sports Med 2017;36:355-368. https://doi. org/10.1016/j.csm.2016.11.007

2. Smith H, Peek Asa C, Nesheim D, Andrew N, Pamela $\mathrm{N}$, Sherly S. Etiology, diagnosis, and characteristics of facial fracture at a midwestern level I trauma center. J Trauma Nurs 2012;19:57-65. https://doi.org/10.1097/ JTN.0b013e31823a4c0e

3. Samieirad S, Tohidi E, Shahidi Payam A, Maryam Alsadar H, Ali A. Retrospective study maxillofacial fractures epidemiology and treatment plans in Southeast of Iran. Med Oral Patol Oral Cir Bucal 2015;20:729736. https://doi.org/10.4317/medoral.20652

4. Lee K. Global trends in maxillofacial fractures. Craniomaxillofac Trauma Reconstr 2012;5:213-222. https://doi.org/10.1055/s-0032-1322535

5. Boffano P, Kommers SC, Karagozoglu KH, Forouzanfar T. Aetiology of maxillofacial fractures: a review of published studies during the last 30 years. British Journal of Oral and Maxillofacial Surgery 2014;52:901906. https://doi.org/10.1016/j.bjoms.2014.08.007 
6. Bocchialini G, Ambrosi S, Castellani A, Negrini $S$, Zanetti $U$, Rossi A. Six years of experience in treating facial trauma in the province of Brescia, Italy. Craniomaxillofacial Trauma Reconstruction Open 2018;2:61-69. https://doi.org/10.1055/s-0038-1675216

7. Shahim FN, Cameron P, McNeil JJ. Maxillofacial trauma in major trauma patients. Australian Dental Journal 2006;51:225-230. https://doi. org/10.1111/j.1834-7819.2006.tb00433.x

8. Motamedi MHK. An assessment of maxillofacial fractures: a 5-year study of 237 patients. Journal of Oral and Maxillofacial Surgery 2003;61:61-64. https:// doi.org/10.1053/joms.2003.50049

9. Samieirad S, Tohidi E, Shahidi Payam A, Hashemipour MA, Abedini A. Retrospective study maxillofacial fractures epidemiology and treatment plans in Southeast of Iran. Med Oral Patol Oral Cir Bucal 2015;20:729736. https://doi.org/10.4317/medoral.20652

10. Ahmed HEA, Jaber MA, Abu Fanas SH, Karas M. The pattern of maxillofacial fractures in Sharjah, United Arab Emirates: a review of 230 cases. Oral Surg Oral Med Oral Pathol Oral Radiol Endod 2004;98:166-170. https://doi.org/10.1016/j.tripleo.2004.01.020

11. Agarwal P, Mehrotra D, Agarwal R, Kumar S, Pandey R. Patterns of maxillofacial fractures in uttar pradesh India. Craniomaxillofac Trauma Reconstr 2017;10:4855. https://doi.org/10.1055/s-0036-1597581

12. Jeon EG, Jung DY, Lee JS, et al. Maxillofacial trauma trends at a tertiary care hospital: a retrospective study. Maxillofac Plast Reconstr Surg 2014;36:253258. https://doi.org/10.14402/jkamprs.2014.36.6.253

13. Kim HG, Son YH, Chung IK. Facial bone fracture patients visiting Pusan national university hospital in Busan and Yangsan: trends and risks. Maxillofac Plast Reconstr Surg 2014;36:140-145. https://doi. org/10.14402/jkamprs.2014.36.4.140

14. Gassner R, Tuli T, Hächl O, Rudisch A, Ulmer H. Cranio-maxillofacial trauma: a 10 year review of 9,543 cases with 21,067 injuries. J Craniomaxillofac Surg 2003;31:51-61. https://doi.org/10.1016/S10105182(02)00168-3

15. Girotto JA, MacKenzie E, Fowler C, Redett R, Robertson B, Manson PN. Long-term physical impairment and functional outcomes after complex facial fractures. Plast Reconstr Surg 2001;108:312327. https://doi.org/10.1097/00006534-20010800000005

16. Motamedi $\mathrm{MH}$. An assessment of maxillofacial fractures: a 5-year study of 237 patients. J Oral Maxillofac Surg 2003;61:61-64. https://doi.org/10.1053/ joms.2003.50049

17. Dimitroulis G, Eyre JA. 7-year review of maxillofacial trauma in a central London hospital. $\mathrm{Br}$ Dent J 1991;170:300-302. https://doi.org/10.1038/ sj.bdj.4807522
18. Telfer MR, Jones GM, Shepherd JP. Trends in the aetiology of maxillofacial fractures in the United Kingdom (1977-1987). Br J Oral Maxillofac Surg 1991;29:250-255. https://doi.org/10.1016/02664356(91)90192-8

19. Asadi SG, Asadi Z. Sites of the mandible prone to trauma: a two year retrospective study. Int Dent J 1996;46:171-173.

20. Eidt JMS, De Conto F, De Bortoli MM, Engelmann $\mathrm{JL}$, Rocha FD. Associated injuries in patients with maxillofacial trauma at the hospital são vicente de paulo, passo fundo, Brazil. J Oral Maxillofac Res 2013;4:1 https://doi.org/10.5037/jomr.2013.4301

Etik kurul onayı: Çalışma için Pamukkale Üniversitesi Girişimsel Olmayan Klinik Araştırmalar Etik Kurulu'nun 13.10.2020 tarih ve 60116787-020/64739 sayı numarası ile etik onayı alınmıştır.

\section{Yazarların makaleye olan katkıları}

E.A. çalışmanın ana fikrini ve hipotezini kurgulamıştir. B.G.T. teoriyi geliştirmiş, gereç ve yöntem bölümünü düzenlemiştir. Sonuçlar kısmındaki verilerin değerlendirmesini B.G.T. yapmıştır. Makalenin tartışma bölümü B.G.T tarafından yazılmıştır. E.A. gözden geçirip gerekli düzeltmeleri yapmış ve onaylamıştır. Ayrıca tüm yazarlar çalışmanın tamamını tartışmış ve son halini onaylamıştır. 